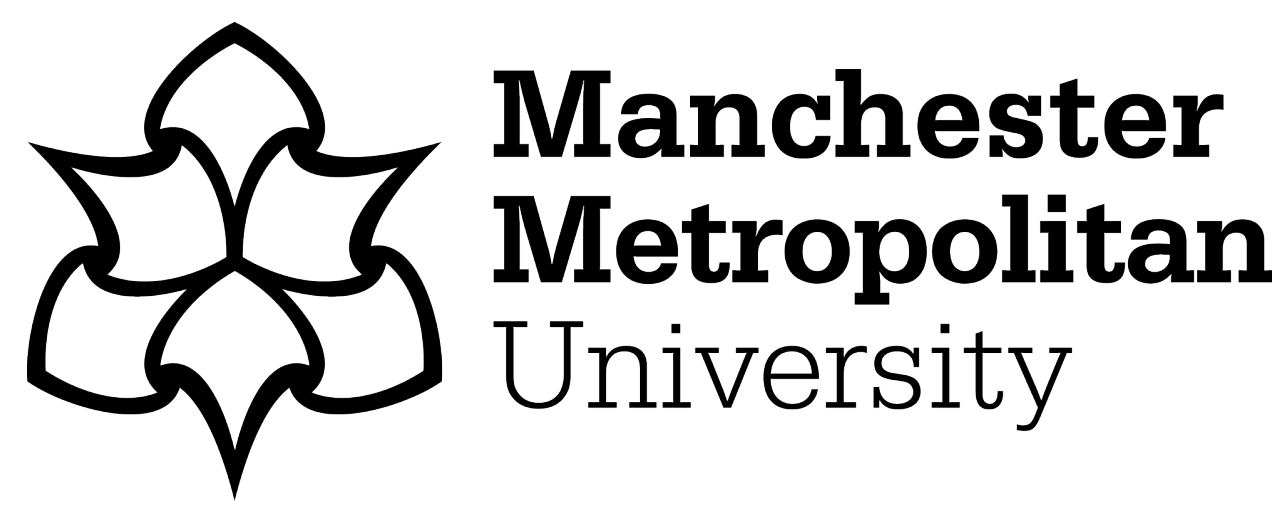

Jagodzinski, P and Archer, Dawn (2018) Co-creating customer experience through call centre interaction: Interactional achievement and professional face. Journal of Politeness Research, 14 (2). pp. 257-277. ISSN 1612-5681

Downloaded from: https://e-space.mmu.ac.uk/621016/

Version: Accepted Version

Publisher: De Gruyter

DOI: https://doi.org/10.1515/pr-2018-0016

Please cite the published version 


\title{
Co-creating customer experience through call centre interaction: Interactional achievement and professional face
}

\author{
Piotr Jagodziński ${ }^{1}$ and Dawn Archer ${ }^{2}$
}

Abstract

Many customer service institutions draw on the (argued over) notion of "customer experience". Gentile et al. (2007) suggest that, at an optimum, the notion assumes a thinking and feeling customer who co-creates their customer experience together, with the service providing institution. This cocreation is believed to comprise interactional involvement, personalisation and the holistic treatment of the customer's needs. Given the latter, we might expect service providers, such as call centres, to view language as a vital means of creating an experience with the customer. The extant linguistic call centre research, including our own, points to the fact that call centre institutions view language as fundamental to their functioning. However, heavy language regulation tends to be the most important - if not the only - means of achieving outstanding customer experience (Cameron 2000; Jagodziński 2013; Archer and Jagodziński 2015). There is a clear mismatch, then, between the tenets of customer experience and the way language is conceptualised, interactionally managed and regulated. Throughout this paper we argue that the co-creation of customer experience must be accompanied by its linguistic co-construction, which can only be achieved by giving frontline employees more interactional freedom than they tend to have in practice.

Keywords: call centre, customer experience, co-construction, interactional achievement

\section{Introduction}

Customer experience is of interest to different audiences for different reasons. The marketing scientists tend to discuss it as a theoretical construct (Lemon and Verhoef 2016). Call centre practice tends to focus on the best means of designing, managing and controlling service interactions, with a view to achieving the best possible customer experience (as measured by various customer satisfaction instruments, including surveys and questionnaires). Linguists have studied both the nature of service encounters in general and call centre ${ }^{3}$ service encounters in particular (see, e.g., Hultgren [2011, 2017]; Márquez Reiter [2009]; Orthaber and Márquez Reiter [2016]). This paper brings these

\footnotetext{
${ }^{1}$ Department of Languages, Information and Communications, Manchester Metropolitan University, Geoffrey Manton Building Rosamond Street West Off Oxford Road, Manchester, United Kingdom, E-mail: p.Jagodzinski@mmu.ac.uk

2 Department of Languages, Information and Communications, Manchester Metropolitan University, Geoffrey Manton Building Rosamond Street West Off Oxford Road, Manchester, United Kingdom, E-mail: d.archer@mmu.ac.uk

${ }^{3}$ In this paper, call centre is being used as a generic term to mean a specialist business organisation (either inhouse or outsourced) solely dedicated to taking or initiating calls to customers.
} 
distinct areas together, in order to demonstrate how linguistic (especially pragmatic) research into service encounters can inform and enrich current thinking in respect to customer experience. Our aims are both theoretical and practical, namely, identifying:

1) The points of convergence between customer experience research and linguistic research in terms of the conceptual apparatus used to construct the notion of customer experience.

2) The role of language and communication in marketing discursive conceptualisations of customer experience.

3) Whether/how the findings of marketing research are translated into call centre practice.

The more theoretically-oriented sections of the paper (2-2.2) are designed to serve as a backdrop to the empirical sections, in which we analyse excerpts of a call centre interaction, collected as part of Jagodziński's (2013) fieldwork at an outsourced airline call centre based in Poland 2009-2011 (3-3.4). Our overarching aim is to contribute to a better understanding between, first, researchers working within differing research paradigms ${ }^{4}$ such as intercultural pragmatics, politeness research and interactional sociolinguistics and, second, researchers and practitioners who might want to adopt the findings as a means of enriching their day to day institutional practices (see especially section 4).

\section{Customer experience as a journey}

Although the notion of customer experience is still proving difficult to define (see, e.g., Gentile et al. [2007]), a central metaphor used in most definitions is that of a journey. Lemon and Verhoef (2016: 2) emphasize how "customers now interact with firms through myriad touchpoints in multiple channels and media, resulting in more complex customer journeys", for example. In our paper we focus on the telephone service encounter. This involves a customer, i.e. the service seeker, interacting with a representative of an airline company. The former will typically interact with the latter in order to make a booking over the telephone or to enquire about specific aspects of their flight. Telephone interactions are therefore one of the most important touchpoints in the airline customer's journey (Laming and Mason 2014: 15). These encounters also tend to be the most discursive of the "myriad touchpoints" (Verhoef 2016: 2), not least because the caller's/agent's "temporal co-presence" (Brünner and Graefen 1993:2) is not required for online touchpoints such as check in procedures. This means that linguistic resources are the means via which callers and call centre agents co-create the

\footnotetext{
${ }^{4}$ This paper seeks to bring together particular paradigms, as a means of facilitating inter-professional dialogue between them. There are additional approaches, focussing on the call centre, which may also offer valuable insights (depending upon research interest), including: corpus linguistics (cf. Friginal 2008), conversation analysis (Orthaber 2017), occupational psychology (cf. Grandey et al. 2004) and applied linguistics (cf. Forey and Lockwood 2007, Forey and Lockwood 2010).
} 
customer experience (cf. Cameron 2003: 59). Hence, Félix-Brasdefer's (2015: XV) observation that service encounters "are the result of co-constructed actions, discursive practices, and language use in context". It also means that call centre service encounters are both a linguistic product and a linguistic process.

Our understanding of the overall customer experience as both process and product (of the customer's journey) does not mean that it equates to a mathematical sum of respective "experiences" at given touchpoints. For a positive experience at a single touchpoint is frequently capable of outperforming a negative experience at other touchpoints. A negative experience can also "weigh" more than the positive experiences at all the other touchpoints, when considered more globally. Jagodziński's (2013) fieldwork in the airline call centre based in Poland supports this claim. He observed that a negative assessment of the quality of call centre interaction by the customer very frequently resulted in a negative overall assessment of the quality of service provided by the airline company. An obvious conclusion is that, from a customer's perspective, customer experience can boil down to a single, telephone-mediated service interaction with a single representative of the company. Customer service interaction seen through the prism of its mostly discursive character, coupled with the non-additive nature of customer experience for the customer, points to an additional conclusion, in turn: that understanding how customer experience is linguistically co-created is crucially important if we are to have a thorough understanding of the concept. ${ }^{5}$

\subsection{Customer experience and the call centre practice}

The importance of the notion of customer experience for call centre practice is evident in the daily functioning of the call centre as a business institution. Indeed, some companies, including the one from which our dataset was taken, go as far as to label their places of work, Customer Experience Centres for example, and to label their representatives, Customer Experience Champions. ${ }^{6}$ This is done so as to emphasise the company's adherence to the tenets of Customer Experience, as well as to underline the exceptional quality of service received by each and every calling customer. The intended emphasis is that these companies consistently go beyond what is expected by customers, by anticipating and (where possible) exceeding their needs.

Contrary to what the marketing literature would suggest, the notion of customer experience is rarely defined explicitly for new call centre agents. Rather, they become familiar with institutionspecific understanding(s) of the notion (including un/acceptable ways of communicating with callers) during their-product and soft-skills training and/or via their company's quality guidelines,

\footnotetext{
${ }^{5}$ This argument is further supported by evidence from Dimension Data (2015) which suggests that more than two-thirds (i.e. 68\%) of an UK's agent workday is spent in interaction with customers.

${ }^{6}$ For the terminological differences between call centre and contact centre see Taylor et al. (2002).
} 
prescriptions, slogans, questionnaires, service scenarios, etc. (cf. Hultgren 2017). Given agents are expected to communicatively enact (the ideal of) customer experience during individual, telephonemediated interactions, in (airline) call centres, we believe service interaction should be perceived as the primary locus of the customer experience in theory as well as in practice (see especially section 4). But this necessitates moving away from call centre practitioners' conceptualisations of customer experience as a positive or negative outcome of a quality assurance procedure (cf. Friginal 2013: 27), based on an assessment of the service interaction according to rigid, pre-designed quality guidelines (see Jagodziński [2013], Archer and Jagodziński [2015]). ${ }^{7}$ This is especially pertinent given that the quality control procedure frequently boils down to a quality coach listening to a recorded conversation and going through a "box-ticking exercise" to see if a particular agent has adhered to the guidelines. In this way, very little attention is paid to the unfolding and negotiation of (interpersonal) meanings in the course of the service encounter.

It is worth noting that the customer service agent tends to be held solely responsible for the outcome (positive or negative) of this quality assurance procedure, i.e. it is his/her (contractual) responsibility to make sure that the quality expectations have been met - and exceeded, preferably. This stems from two related assumptions about the nature of communication and language. First, that it can be regulated, managed, controlled and pre-defined for the agent (cf. Hultgren 2011, 2017). Second, that the agent can implement the quality guidelines such that $s /$ he creates the customer experience not co-jointly with, but frequently in spite of the calling customer (especially in conflictive or openly confrontational interactions). The calling customer rarely (if at all) enters the picture, and, when they do, their presence is reduced to being a token whose qualities and attributes are often over-simplistically sketched in the course of soft-skills training as part of the so-called customer taxonomy model. This commodification of language, as Cameron (2000) calls it, runs contrary to pragmatic accounts of meaning, which emphasise its co-construction "in the moment", rather like the creation of jazz (cf. musicians "following a score") (Arundale 2009: 44). It also runs contrary to the understanding, within the marketing literature, that customer experience is a co-creation between the representative of the company and the client.

If we subscribe to what marketing literature has to say about customer experience and to what pragmatics has to say about meaning - namely, that the former is co-created and the latter is interactionally co-constructed - a question we might ask centres upon the operational definition of a successful service encounter. This paper presents a data-driven understanding of the notion of Customer Experience, with the aim of providing an answer that can be incorporated into call centre practice. Indeed, our aim is to help institutional practitioners distinguish successful and unsuccessful

\footnotetext{
${ }^{7}$ For examples of call centre quality questionnaires see (cf. Friginal 2008: 333-337).
} 
interactions based upon assessing the service encounter as it progresses - including noting those moments when it regresses - rather than on the basis of arbitrary, top-down quality criteria. Alternatively, this (more interactional) approach might be drawn upon to corroborate (thereby in/validating) such scores. We begin with the understanding that - in settings such as inbound airline call centres, where agents habitually deal with complaints as well "regular" customer service (Jagodziński 2013) - a level of customer resistance to company quality standards/guidelines, etc., can be anticipated. Hence, our focus upon noting the moments when an interaction regresses, as well as those moments when it progresses (see above: see also Sections 3-4). As our previous work has shown (Archer and Jagodziński 2015), it is possible to identify the resistance strategies that are commonly employed in such settings, by customers, in ways that allow agents to repair the interaction (for the mutual benefit of caller and company). To expand on the metaphor that Arundale (2009) used to explain Face Constituting Theory, this would be akin to acknowledging that the sound being created, by agent and caller, can sometimes sound more akin to a "din" than jazz, until each of them find a resonance with the other. As will become clear, we particularly draw upon the notions of (1) professional face and, to a lesser extent, (2) activity type in this paper. In respect to (1), we make use of Jagodziński's (2013) data-driven notion of professional face (cf. Orthaber and Márquez Reiter 2011), given it was the basis for a facework model capable of explaining face considerations that emerge in the course of (conflictive) call centre service encounters. According to this model, a call centre agent can interactionally project two faces: personal and professional. Professional face comes about because of the metonymic (cf. Bousfield 2013) relationship that emerges between the agent and the company s/he represents. Jagodziński (2013) and Archer and Jagodziński (2015) argue that, for the duration of the interaction, the agent can therefore be seen as embodying the company (see section 2.2 , following). ${ }^{8}$ In respect to (2), we concur with Culpeper's (2011: 196) characterisation of an activity type as "a collection of (...) conversational contributions, including speech acts that stand in a particular pragmatic relationship to each other and have become a relatively conventionalised whole." As Culpeper goes on to explain, this notion can help us to capture both how context shapes the language and also how language shapes the context (see also Levinson 1992).

\subsection{Towards an interactional definition of customer service experience}

When agents are operating within their role, they become representatives of the company, such that their professional identity (and hence professional face) is foregrounded. Indeed, they tend to be required to maintain a consistent professional face in interactions with customers irrespective of the

\footnotetext{
${ }^{8}$ This, in and of itself, constitutes another argument (see section 2 above) for the treatment of the call centre interaction as the primary locus of customer experience.
} 
channel of communication. ${ }^{9}$ Personal face may still feature (especially in conflictive exchanges), of course, but it is usually deemed to be secondary to, and thus tends to be interactionally evoked less frequently than, professional face (see Jagodziński 2013; Archer and Jagodziński 2015). Face (professional or personal) is not considered, by us, to be a private possession (permanently) lodged in an individual. Rather, face is shaped dynamically in interaction by both parties (see Section 2.1, and Arundale 2009). Our understanding of the customer service experience seeks to capture this interactional aspect, as well as move practitioners away from an understanding of call centre agents as "rule followers" only (cf. Arundale 2009: 39). We thus advocate that the call centre Service Experience be seen as an interactional outcome, i.e. a joint, linguistically co-constructed endeavour transpiring between the calling customer and the customer service representative. This may or may not include the need to overcome conflicting "wants" and, hence, resistance (see Section 2.1, and also Sections 3-3.4). As such, we also advocate that agents be given the maximum possible interactional freedom to be able to pro-actively negotiate any emerging face considerations, whether they relate to the face of the company they represent, their own personal face and/or the face "wants" of the customer (Brown and Levinson 1987). The forthcoming sections draw on extracts from a call centre interaction to demonstrate the dynamic nature of facework (see Sections 3-3.4) in this context, before demonstrating how our understanding of the customer service experience might be operationalised in this activity type (see Section 4). The extracts are part of the 100,000 word plus dataset collected by Jagodziński (2013), during his ethnographic fieldwork in 2009-2011, at an outsourced airline call centre located in Poland. This particular airline call centre expected their staff to converse with callers in English.

\section{Data Analysis}

Sections 3.1 to 3.4 are based upon four extracts (A-D) taken from a representative interaction between the calling customer and the customer service agent (Jagodziński 2013). The interaction is representative in the sense that the agent is caught between the need to adhere to the call centre quality guidelines and the situated here-and-now of the unfolding interaction. We are focussing on these particular extracts because they have implications for the faces of both interlocutors. They each experience face damage in the course of (what proves to be a conflictive) exchange, for example, with the agent in particular experiencing threats to both his professional and personal face.

\subsection{Changing (details respecting) a flight}

\footnotetext{
${ }^{9}$ Within the marketing science literature on customer experience there are frequent references to the so-called 'omnichannel challenge', i.e. the difficulty of providing consistent customer service through different channels, e.g. telephone, internet and face-to-face.
} 
Extract A centres around a caller's desire to amend details respecting her flight. When making her booking, she had provided the airline with an anticipated due date for her unborn child but the child had arrived on a different day. This particular exchange between the caller and the call centre agent (the duty manager for this particular shift) occurred as a result of her request to speak with someone more senior, once her previous interactions with the call centre failed to result in a fee waiver.

\section{Extract A: Changing (the details of) a flight}

1 A: hello mrs XXXXX hello my name is XXXXX I'm the manager on duty today C: $\quad$ Hello

2 A: how can I help you

C: $\quad<$ indistinct $>$ I thought I could go on line and change my flight

3 A: yes

$\mathrm{C}$ : $\quad$ and it's costing me two hundred and eighty pounds to change the

4 A:

C: accommodation I didn't realize I don't have two hundred and eighty pounds

5 A: all right then I can confirm that as it is stipulated in our terms and conditions and $\mathrm{C}:$

6 A: carriers regulations you agreed to at the time of booking each change requires a C:

7 A: certain change fee to be paid plus the difference in the seat price and obviously $\mathrm{C}:$

8 A: that depends on the

$\mathrm{C}$ : $\quad$ indistinct $>$ I work for a travel company

9 A: advise you is that if you change the flight over the phone then the change fee $\mathrm{C}$ :

10 A: is even higher than those on the internet because on the internet you have thirty C:

11 A: pounds per passenger per flight over the phone it's forty pounds per person per C:

12 A: flight and here this change is applicable per each flight changed ..so it's one C:

13 A: hundred and twenty which is only the change
C: $<$ indistinct $>$

fee if you can see the

14 A: cost of the flight is less than the change fee itself then it might be better to look $\mathrm{C}$ :

$15 \mathrm{~A}$ : at the flights again instead of changing the existing booking because sometimes

16 A:
C:

17 A:

$\mathrm{C}$ : pounds is a lot of money for changing a flight $<$ indistinct $>$ where I work I manage

18 A:

C: to change people's flights through my company the booking I've done privately I

19 A: here we do not have any case where we can change the flight for free C: can't 
Extract $A$ begins with the caller explaining the issue with respect to the date-of-birth change and her aborted attempt to amend the detail via the internet (see line 2). It is worth noting, here, that the agent will have had access to the notes made by previous agents, respecting the caller not wanting to pay the change fee charge (for each person per flight). Although the caller does not make this immediately clear at the outset of her conversation with this agent, she does make the agent aware of a lack of funds on her part, by commenting upon the additional cost of her accommodation-related changes: I don't have two hundred and eighty pounds. In response (lines 5-7), the agent opts to corroborate what the caller will have already been made aware of: namely, that requiring passengers to pay a certain change fee is official company policy, and that this is something the caller will have agreed to at the time of booking. This response serves at least three purposes, from the agent's perspective. First, her presupposition that the caller had foreknowledge of airline policy (emphasised via phraseology such as I can confirm... regulations you agreed to at the time of booking) serves to shift the blame for the fee change onto the caller herself. Second, it fulfils the company's quality guideline requirement relating to the airline policy being explained to the caller. Third, it demonstrates that, from the perspective of face, the line the agent is taking (cf. Goffman 1967) is that of company representative: see, for example, her use of as it is stipulated in our terms and conditions. By opting to adopt a transactional frame (in spite of the caller's apparent preference for a more personal frame), the agent not only failed to address the face needs of the caller, but, in fact, served to threaten her positive face (i.e., her "want" to be approved of: Brown and Levinson 1987). At best, she was implicating the caller had not been competent enough to check their regulations when booking with them. At worst, she was potentially implying that the caller was aware of the regulations, but was lying about this in an attempt to persuade the company to waive the fee. The caller's utterance in line 8 is worthy of note, in this regard. I work for a travel company was most likely a persuasive attempt on the caller's part to signal her knowledge that such requests can be accommodated, if a company so desires. However, it is also possible to argue that, as a comparable professional, she should not only be aware of but also understand the technicalities of the booking process. The agent offers some advice in response to the caller's self-disclosure at this point. That advice relates to using the internet to change the flight as it is cheaper, and checking whether the cost of the flight is less than the change fee with a view to making a completely new booking (see lines 8- 15). Here, the agent shows herself to be attentive to the caller and thus her face needs, as she values her enough to want to help her to save money (cf. Brown and Levinson's 1987 positive face). This may be because this particular facemaintaining behaviour is in line with the company's quality guidelines, which require agents to put themselves metaphorically in their customer's shoes so that they might provide customers with advice (rather than instructions) as to their best course of action. As lines 17-19 reveal, the caller does not 
accept the advice, preferring instead to enhance her own face by stating that she is the type of person who manage(s) to change people's flights. This second self-disclosure (on the caller's part) effectively intimates, via an implicit contrast, that the agent is not the type of person to do her job well (thereby threatening both her professional face and personal face). The agent responds by differentiating her own company's policies from those of the caller's: here we do not have any case where we can change the flight for free (line 19). Notice that the wording allows for changes to be made, but not for free (as the caller desires).

\subsection{Extract B: You're not offering me anything are you}

Extract B, following, relates to the mid-point in their exchange (lines 39-52).

\section{Extract B: You're not offering me anything are you}

39 A: transport of a passenger from one airport to another $\mathrm{C}$ : $\quad$ not if you have to pay another

40 A:

C: hundred and twenty pounds on top of what you've just paid it's not a low cost

41 A: $\quad$ here in the case of low cost airlines all additional services must be C: $\quad$ flight is it

42 A: additionally paid otherwise we wouldn't be able to operate well simply this is C:

43 A: how it works I'm sorry if this is not the best solution for you however this is the C:

44 A: best thing I can offer you here ... well $\mathrm{C}$ : $\quad$ you're not offering me anything are you

45 A: here I can advise you that the change fees on-line are lower than those over the C:

46 A: phone and if you're looking $\mathrm{C}$ : could you waive the half of the fee

47 A: able to change the C: $\quad$ <indistinct> I wasn't planning on that

48 A: understand that however those fees are not flexible I cannot apply them at any C:

49 A: level I wish they're certain fixed fees that are applied for a change here if you C:

50 A: have travel insurer I can suggest maybe contacting travel insurers if this is sort C:

51 A: of medical issue maybe they would be willing to accept your claim hello C:

52 A: can you hear me . maybe they'll be willing to accept your claim and then of course In the initial utterance above (captured by lines 39-41), the caller points out that the flight is not proving to be low cost. Indeed, her conditional + contradictory statement + confirmation-seeking tag serve to emphasise that this particular budget airline is failing to provide the service it claims to (i.e., affordable flights for passengers). Archer's (2011) Face Aggravation Scale is worthy of note, at this 
point. FAS contains a strategic ambivalence facework zone as well as intentional and incidental facework zones (inspired by Goffman 1967). The former captures interlocutors' use of "linguistically aggressive behaviour" (Archer 2011a: 3220-3221) as part of their role: as a means of undermining another, for instance. From a facework perspective, the behaviour thus falls between unplanned byproducts of the interaction (cf. Goffman's incidental level of face threat) and malicious and spiteful acts (cf. intentional impoliteness). The conditional + contradictory statement + confirmation-seeking tag (in lines 39-41) is not overtly impolite, for example, but it is worded in such a way as to elicit agreement with the (indirect) criticism of the company. This company's protocol prohibits agents from criticising it (or its practices), which may explain why the agent fails to answer yes or no and, instead, focuses upon explaining that low cost airlines work by getting their customers to pay for all additional services (lines 41 and 42). This adherence to the prescribed strategies is not well received, by the caller, even though the agent also provides an apology and attempts to empathise with the caller by stressing that it is the best thing she can offer (line 43). This may be because the apology acknowledges her recognition that this was probably not the best solution for the caller, thereby allowing the caller to ask a second, more damning question: you're not offering me anything are you (line 44). Notice that this particular question echoes the agent's previous mention of offer (line 44), as a means of highlighting that the company is not offering anything specifically to her, the individual caller. Instead, she is being told (repeatedly) about company policy.

Archer (2011b: 75, 2011b: 86) suggests that, in some conflictive contexts, face-threatening strategies can point to the interlocutors' (often incompatible) perceptions of reality - and, by extension, the "truth filters" they may be using "to make sense of their world" (which Archer 2011b refers to as reality paradigms). This is especially evident in the caller's case. The caller not only wants the agent to - but also seems to believe she can - waive all or part of the fee (see, e.g., line 46). The agent responds by repeating her earlier advice (see lines 44-46), in line with her company's quality policy. The caller then makes clear that she wasn't planning on the caller being unable to fulfil her wants. The agent's strategy, at this point, is to assure the caller that she can perfectly understand her situation whilst explicitly maintaining that those fees are not flexible (lines 47 and 48). She also offers the caller an alternative route forward, involving contacting travel insurers to see whether they would be willing to accept the claim as a sort of medical issue (lines 49-52). In doing so, the agent defends her professional face and simultaneously attempts to maintain the caller's face.

\subsection{Extract C: You're not very helpful}

Extract $\mathrm{C}$ captures a point in the exchange where the interaction becomes more confrontational. 


\section{Extract C: You're not very helpful}

70

C: $\quad$ you know $<$ indistinct> but you're not very helpful you know what I

71 A: $\quad$ mrs $X X X X X$ we're a low cost airline

$\mathrm{C}$ : mean you don't have to waive the whole charge

72 A:

C: just a half of it you know a hundred and twenty pounds is a lot of money

73 A: understand that however well this is a low cost airline and $<$ indistinct $>$ must be

C:

74 A: pretty restrictive otherwise there wouldn't be any sense for the airline for operating

C:

75 A: they won't be able to earn for themselves this is how it works this is the very basic

C:

76 A: policy and I'm really not able to waive even a part of this $\mathrm{C}$ :

77 A:

C: because a friend of mine travelled at Christmas times .. completely different flight

78 A:

C: and they didn't have to pay any extra <indistinct> so now it's rubbish what you're

79 A:

C: saying because she's done it

as I said the free flight change is possible only in the

80 A: case of flight disruption you can transfer for free to another flight on the same

C:

81 A: route to the next available one or another one at your convenience however this is

$\mathrm{C}$ :

$82 \mathrm{~A}$ : in very specific cases where something goes wrong on our side $\mathrm{C}$ :

83 A:

C: I'm not asking to go I just wanna go on a different day and $<$ indistinct $>$ well a

84 A:

$\mathrm{C}$ : hundred and twenty pounds is a lot of money

do you know what I mean

I'm sure

well I'm sorry that you feel this

85 A: way but there's really nothing I can do

C:

well fantastic $<$ indistinct $>$

Notice how the caller undermines the agent's efficiency/competence in her initial utterance, thereby directly and simultaneously attacking her personal and professional face: you're not very helpful (line 70). The agent then defends herself by reiterating the company's (admittedly restrictive) basic policy: that low cost airlines make their living by not waiving additional fees, where applicable (lines 71-76). This prompts the caller to negatively evaluate the caller's statement as rubbish ( $\mathrm{x} 2)$. She also provides her reasoning: a friend of mine travelled at Christmas time completely different flight and they didn't have to pay any extra (see lines 76-79). The agent responds by explaining that the free flight change is possible only in the case of flight disruption (lines 79 and 80), which seems to contradict her earlier claim that the company does not have any case where changing the flight for free is permissible (line 19: see also 3.1). It is worth noting that the preface used by the agent at this point - as I said (line 79) - is prescribed by the company's protocol (for such conflictive situations). Note, however, that as I said 
not only makes clear that the speaker is repeating something they have said before, but also implicates that his/her interlocutor is not comprehending or, worse, purposely not accepting what has been said. It can thus have positive face implications for the receiver (by, e.g., insinuating that $s /$ he is obtuse or ignorant). The caller's response - do you know what I mean (line 82) suggests a level of annoyance, on her part, that she is not being understood (or, at least, listened to), which would have positive face implications for the agent in turn. The caller then re-attempts to get the agent to waive the fee and the agent once again expresses empathy (I'm sorry that you feel this way) before emphasising that there's nothing she can do (lines 84-85). This latter admission fails to act according to the company's prescribed guidelines, which stipulate that agents should always use what they refer to as "positive language" (Cameron 2008: 149). When the caller intimates that a hundred and twenty pounds is a lot to pay to go on a different day (lines 83 and 84), and the agent reiterates her apology followed by her admission that there's really nothing she can do (lines 84 and 85 ), the caller resorts to sarcasm: well fantastic (line 85). The sarcasm points to the caller's ongoing dissatisfaction over the agent's lack of compliance (from her perspective) as well as constituting another attack of the agent's face.

\subsection{Extract D: So basically you're not gonna help me}

Extract D captures the closing stages of the agent's exchange with the caller.

\section{Extract D: So basically you're not gonna help me}

90 A: time of booking however in your can however
C:
it's not twenty four hours is it . it's about a week

91 A: even if you cancel your flight within twenty four hours there is a cancellation fee $\mathrm{C}$ :

$92 \mathrm{~A}:$ than is even higher than the price of the flight you got what you can claim back $\mathrm{C}$ :

93 A: from this booking is the amount of the airport taxes and the total amount for this $\mathrm{C}$ :

94 A: booking is twenty four pounds . so this is what you can claim back if you decide C:

$95 \mathrm{~A}:$ not to change the flight not to travel $\mathrm{C}$ : $\quad$ all right twenty four pounds

96 A: amount for the airport taxes the airline doesn't pay this in the case the passenger $\mathrm{C}$ :

97 A: does not travel so then this amount is C: $\quad$ so basically you're not gonna help me

98 A: mrs this is our basic policy $<$ indistinct $>$ no $\mathrm{C}$ : nothing you could do $<$ indistinct $>$

99 A: other solution is possible at this very moment in this case so C: $<$ hangs up $>$

The agent speaks the most in this exchange, but her strategy remains the same: reiterating the airline's policy to the caller. This includes explaining the cancellation fee as well as the amount she can claim 
back (lines 91-97). The caller remains quiet during most of this exchange, which may suggest that she is in the process of extricating herself from the interaction. As Sifianou (1997: 79) notes, silence can be used for both polite and impolite purposes. We would argue that the silence, in this case, has more to do with the latter than the former, given how the interaction has played out up to this point. The silence is only temporary, however, as the caller suddenly interrupts the agent's turn to affirm her recognition that she is not gonna get the help she wants (line 97).

Notice that the agent's talk overlaps the caller's in the next turn (line 98). As with silence, overlapping talk does not have to be conflictive, and it is not treated explicitly as "a "trouble' in the exchange" by either participant (Hutchby and Wooffitt 2008: 172). A conflictive interpretation seems reasonable, nonetheless, given three observable factors:

1) The agent and caller's choice of words.

2) The caller resorting to silence as the agent continues to reiterate that no other solution is possible at this very moment in this case (lines 98 and 99).

3) The caller hanging up on the agent shortly thereafter.

Although callers, as call-initiators, have the right to initiate the closing in telephone exchanges (Sacks 1992; Schegloff and Sacks 1973), ending the call in this way is highly marked behaviour. Indeed, closings are such delicately-balanced, ritual acts (Kádár 2013: 99) that a lack of a conventional closing would equate to withholding politeness (Bousfield 2008) for most interlocutors, even for this particular activity type. We might note, for example, that telephone closings are typically initiated by a specific pre-closing marker, such as right, alright, yes, uh uh and ok (Schegloff and Sacks 1973; Stenström 2014), followed by appreciation (where applicable) and a farewell terminal exchange (i.e., a greeting/greeting adjacency pair [Button 1987]; [Schegloff 2007]). The caller's final attack on the agent's face may have been triggered, by the agent once again resorting to (what Button [1987] has labelled) back-referencing behaviour. This equates to re-topicalising what has already been presented at several points throughout the exchange (albeit in different ways, in this case). According to Orthaber (2014: 162), when used by agents on callers, back-referencing behaviour has the potential to be understood (by the latter) as a reprimanding move, occasioned by their "not paying attention to what ha[s] already been said", and for threatening the agents' professional face in consequence 


\section{Conclusion and recommendations for call centre practitioners}

This paper has sought to identify points of convergence and divergence between the practice of customer service and how it is theorised within both the marketing literature and extant linguistic studies. Our motivation has been three-fold:

1. To help researchers within these paradigms better understand the approach of the other.

2. To demonstrate how their understanding of the concept of customer experience might enrich and/or detract from the day-to-day institutional practices of the call centre.

3. To provide call centre practitioners with empirically validated ways of improving their customer's actual experiences.

In respect to 1 , we have noted how call centre practitioners make their agents solely (and hence contractually) responsible for enacting (their notion of) customer experience during telephone mediated interactions with callers: such that they are expected to meet and, ideally, exceed their caller's expectations. An agent's success (or lack of) in this regard tends to be measured by his or her adherence to rigid, pre-designed quality guidelines supplied by their company (cf. Friginal 2013: 27; see also Jagodziński [2013]; Archer and Jagodziński [2015]). This type of understanding of customer experience is underpinned by two related assumptions. First, that language (and hence communication) can be regulated, managed, controlled and pre-defined for the agent (cf. Cameron 2000, Cameron 2008). Second, that the agent can thus implement the quality guidelines such that $\mathrm{s} /$ he creates the customer experience not co-jointly with, but frequently in spite of the calling customer (especially in conflictive or openly confrontational interactions). As we noted in section 2.1, this commodification of language (Cameron 2000) stands in stark contrast to pragmatic accounts of meaning, which emphasise its co-construction "in the moment" (see, e.g., Arundale's [2009: 44] jazz analogy), and the marketing literature, which sees customer experience as a co-creation between the representative of the company and the client. Our approach is similar to the latter. This is to say, this paper argues against the idea of agents as "rule followers" only and advocates, instead, for the call centre service experience to be seen as a linguistically co-constructed endeavour involving both the calling customer and the customer service representative (see section 2.2). Although we have drawn upon Arundale's jazz analogy in this paper, we have also been careful to acknowledge the potential shaping effects of the activity type represented by our dataset. For example, inbound airline call centres can anticipate some level of conflict with and/or resistance from callers, given their agents have to habitually deal with complaints as well "regular" customer service (Jagodziński 2013). This serves to explain our focus upon the moments when an interaction regresses, as well as those 
moments when it progresses, when analysing the four extracts taken from a single call centre interaction collected by Jagodziński (2013) (see Sections 3-3.4). In Section 2.1, we likened this to acknowledging that the "sound" created, by agent and caller, can sometimes be more akin to a "din" than jazz (cf. Arundale 2009). Although the ideal remains that of agent and caller finding a resonance with the other, it means that we must acknowledge this can be extremely difficult: and seems to become especially so in contexts where the need to adhere to the company's quality guidelines seems to have overridden the customer's need for a positive experience in practice (as here). Based on our analysis of the four extracts, we would thus argue for agents to be given the maximum possible interactional freedom to be able to pro-actively negotiate any emerging face considerations, whether they relate to the face of the company they represent, their own personal face and/or the face "wants" of the customer/caller (Brown and Levinson 1987).

This brings us to our second aim. Our analysis sections have revealed that some prescribed practices do have a face-enhancing outcome. Note, for example, the requirement that agents put themselves metaphorically in their customer's shoes so that they might provide them with the best advice (rather than instructions) as to their best course of action (discussed in Section 3.1). In this case, the agent's advice (respecting how the caller might save money) attended to the caller's positive face (Brown and Levinson 1987) to some degree, but her repetition of / can advise/suggest (in lines 8-9, 45 and 50) can be interpreted nonetheless as an attempt to prioritise her professional face (over personal face). It is worth noting, here, that I can advise you is one of the prescribed rapport-building phrases taught to the agents during their soft skills and conflict management training at this company, and that it is frequently used (according to Jagodziński's [2013] wider dataset). The problem that this particular agent had, however, was that their caller's "want" involved not paying for a fee change at all. The agent would not or could not acquiesce to this, as signalled by her strict adherence to the quality guidelines across the four extracts. Our analyses of these extracts suggest that such adherence to prescribed relational strategies can be problematic to the point of becoming a face-aggravating trigger (from the caller's perspective). Indeed, in this case, the caller retaliated/attacked the agent's professional face on each occasion that the agent made use of prescribed strategies. The exchange became gradually more conflictive, in consequence, and thereby resulted in the very opposite of what the notion of customer experience attempts to aspire to: that of maintaining a consistent approach, with the caller, that exceeds their expectations, thereby positively enhancing the face of the company.

It is worth noting that, when the agent tried other prescribed rapport-building phrases, such as I can perfectly understand, for example, it became clear that the caller was using a different "truth filter" of 
how the world works (Archer 2011b) to the agent, based on her own professional experience (see Sections 3.1 and 3.2). The agent was further hampered because of not being able to apologize, as it meant that she could only reiterate her rigid stance, whilst also attempting to come up with alternative positive solutions for the already aggrieved caller (see Sections 3.1-3.4). The prohibition respecting criticism meant that she also struggled when the caller implied that the company was not fulfilling its core aim (and thus behaving contrary to the customer experience ideal expounded by practitioners: cf. Sections 2.2, 3.2 and 3.3).

This brings us to our third aim. We would argue that the top-down approach currently adopted by call centre practitioners effectively forces agents to orient (predominantly) to the transactional elements of exchanges. The downplaying of the interpersonal level seems contrary to Félix-Brasdefer's (2015: $\mathrm{XV}$ ) observation that service encounters "are the result of co-constructed actions, discursive practices, and language use in context" (see section 2). One means of ensuring that agents can focus on the interpersonal as well as the transactional is to unshackle them from the top-down approach. We offer our working definition of customer experience to help practitioners in this regard. We also offer some of the other concepts discussed in this paper, such as professional face and reality paradigms. For example, our experience has shown that the notion of professional face can be operationalised successfully within service-based industries, thereby helping agents (in particular) separate their personal face from their professional duties (see especially Jagodziński 2013). Similarly, understanding that a caller's (face-threatening) behaviour towards an agent may be due to them using "truth filters to make sense of their world" (Archer 2011b: 75, Archer 2011b: 86), which are different to the agent's perceptions of how the world works, may help that agent put themselves metaphorically in their customer's shoes more effectively (cf. Sections 3.1 and 3.2). Learning how to identify reality paradigms (Archer 2011b), from the caller's talk, as well as how to mitigate threats to face using, for example, FAS (Archer 2011a) or similar (Archer and Jagodziński 2015) could easily be implemented within agents' existing training methods. One means of implementing reality paradigm training, for instance, is via the jazz metaphor: such that trainees first learn how to distinguish moments of regression (as "din"). This might then lead into face-threat mitigation exercises, such that trainees draw upon reallife examples to find ways of interacting that would better match their interlocutor's mindset, and hence better serve the customer service ideal (whilst also keeping in mind the company's needs). Such an approach would also provide agents (and their companies) with a safe space via which to consider the most effective strategies for dealing with conflict, when it inevitably arises. The strategies identified by Archer and Jagodziński (2015), in this regard, are based upon Jagodziński's previous role as a call centre trainer for the company under study, as well as his empirical research and his 
continuing links with various call centre operators (across Europe). We are conscious, nonetheless, of the importance of in/validating our findings here and elsewhere through further research, be it our own and/or others. This might relate to similar airline call centres and also other call centres, both inbound and outbound.

\section{References}

Archer, Dawn. 2011a. Libelling Oscar Wilde: The case of Regina vs. John Sholto Douglas. Journal of Politeness Research 7(1). 73-99.

Archer, Dawn. 2011b. Facework and im/politeness across legal contexts: An introduction. Journal of Politeness Research 7(1). 1-19.

Archer, Dawn and Piotr Jagodziński. 2015. Call centre interaction: A case of sanctioned face attack. Journal of Pragmatics 76. 46-66.

Arundale, Robert B. 2009. Face as emergent in interpersonal communication: An alternative to Goffman. In Francesca Bargiela-Chappini and Michael Haugh (eds.), Face, communication and social Interaction, 33-54. London: Equinox.

Bousfield, Derek. 2013. Face in conflict. Journal of Language Aggression and Conflict 1. 37-57.

Button, Graham. 1987. Moving out of closings. In Graham Button \& John R. E. Lee (eds.), Talk and social organization, 101-151. Philadelphia: Multilingual Matters.

Cameron, Deborah. 2000. Styling the worker: Gender and the commodification of language in the globalized service economy. Journal of Sociolinguistics 4.323-347.

Cameron, Deborah. 2008. Talk from the top down. Language and Communication 28. 143-155.

Cameron Deborah and Don Kulick. 2003. Language and sexuality. Cambridge: Cambridge University Press.

Culpeper, Jonathan. 2011. Impoliteness: Using language to cause offence. Cambridge: Cambridge University Press.

Dimension Data. 2015. Global Contact Centre Benchmark Comparison Portal. http://www.ccma.org.uk/benchmarking/benchmarking-reports/

Forey, Gail. and Jane Lockwood. 2007. "I'd love to put someone in jail for this": An initial investigation of English in the business processing outsourcing (BPO) industry. English for Specific Purposes 26. 308-326.

Forey, Gail and Jane Lockwood (eds.).2010. Globalisation, communication and the workplace. London: Continuum.

Friginal, Eric. 2008. The language of outsourced call centers: A corpus-based study of cross-cultural interaction. PhD diss., Northern Arizona University. 
Friginal, Eric. 2013. Evaluation of oral performance in outsourced call centres: An exploratory case study. English for Specific Purposes 32. 25-35.

Gentile, Chiara, Nicola Spiller \& Giuliano Noci. 2007. How to sustain the customer experience: Experience components that co-create value with the customer. European Management Journal 25. 395-410.

Grandey, Alicia A., David N. Dickter \& Hock-Peng Sin. 2004. The customer is not always right: Customer aggression and emotion regulation of service employees. Journal of Organizational Behavior 25. 397-418.

Hultgren, Anna Kristina. 2011. 'Building rapport' with customers across the world: The global diffusion of a call centre speech style. Journal of Sociolinguistics 15. 36-64.

Hultgren, Anna Kristina. 2017. Vocative as rationalised politeness: Theoretical insights from emerging norms in call centre service encounters. Journal of Sociolinguistics 21(1). 90-111.

Hutchby, lan \& Robin Wooffitt, Robin. 2008. Conversation Analysis. 2nd edn. Cambridge and Malden: Polity Press.

Jagodziński, Piotr. 2013. Impoliteness strategies in a British airline call centre: A pragmatic analysis of customer service interactions. PhD diss., Adam Mickiewicz University.

J. César Félix-Brasdefer. 2015. The Language of service encounters: A pragmatic-discursive approach. Cambridge: Cambridge University Press

Kádár, Dániel Z. 2013. Relational rituals and communication: Ritual interaction in groups. Basingstoke: Palgrave Macmillan.

Kádár, Dániel Z. \& Marcel Bax. 2013. In-group ritual and relational work. Journal of Pragmatics 58. 7386.

Laming, Calum \& Keith Mason. 2013. Customer experience - An analysis of the concept and its performance in airline brands. Research in Transportation Business and Management 10. 1525.

Lemon, Katherine N. \& Peter C. Verhoef. 2016. Understanding customer experience throughout the customer journey. Journal of Marketing 80(6). 69-96.

Márquez Reiter, Rosina. 2009. How to get rid of a telemarketing agent? Facework strategies in an intercultural service call. In Francesca Bargiela-Chappini and Michael Haugh (eds.), 55-77. London: Equinox Publishing.

Orthaber, Sara. 2017. (Im)politeness at a Slovenian Call Centre. PhD diss., University of Surrey.

Orthaber Sara \& Márquez Reiter, Rosina. 2016. When routine calls for information become interpersonally sensitive. Pragmatics and Society (7)4. 638-663.

Sacks, Harvey. 1992. Lectures on Conversation (Vol. I: Fall 1964 - Spring 1972). Oxford: Blackwell. 
Schegloff, Emanuel. 2007. Sequence organization in interaction: A primer in conversation analysis. Cambridge: Cambridge University Press.

Schegloff, Emmanuel \& Harvey Sacks. 1973. Opening up closings. Semiotica 8(4). 289-327.

Sifianou, Maria. 1997. Silence and politeness. In Adam Jaworski (ed.), Silence: Interdisciplinary perspectives, 63-84. Berlin and New York: Mouton de Gruyter.

Stenström, Anna-Brita. 2014. An Introduction to spoken interaction. London and New York: Routledge.

Taylor, Phil, Gareth Mulvey, Jeff Hyman \& Peter Bain. 2002. Work organization, control and the experience of work in call centres. Work, Employment and Society 16. 133-150.

Brünner Gisela \& Gabriele Graefen. 1993. Einleitung: Zur Konzeption der funktikonalen pragmatik. In Brünner and Graefen (eds.), 7-24. Texte and diskurse. Opladen: Westdeutcher Verlag. 